\title{
CORRIGENDUM
}

\section{Nuclear E-cadherin and VHL immunoreactivity are prognostic indicators of clear-cell renal cell carcinoma}

Michelle L Gervais, Pauline C Henry, Arthy Saravanan, T Nadine Burry, Brenda L Gallie, Michael AS Jewett, Richard P Hill, Andrew J Evans and Michael Ohh

Laboratory Investigation (2008) 88, 450; doi:10.1038/labinvest.2008.9

Correction to: Laboratory Investigation (2007) 87, 1252 1264; doi:10.1038/labinvest.3700684; published online 1 October 2007

In this article, the third author, Liz Taylor-Edmonds, was omitted from the authors' list. The corrected author's list is as follows:

Michelle L Gervais, Pauline C Henry, Liz Taylor-Edmonds, Arthy Saravanan, T Nadine Burry, Brenda L Gallie, Michael AS Jewett, Richard P Hill, Andrew J Evans and Michael Ohh 